\title{
Comment on "Alpha-Lipoic Acid and Antioxidant Diet Help to Improve Endothelial Dysfunction in Adolescents with Type 1 Diabetes: A Pilot Trial”
}

\author{
Hitesh Verma ${ }^{1,2}$ and Rajeev Garg ${ }^{2}$ \\ ${ }^{1}$ Overseas ReD Centre, Overseas HealthCare Pvt. Ltd., Phillaur, Punjab 144410, India \\ ${ }^{2}$ Department of Pharmaceutics, ASBASJSM College of Pharmacy, Bela, Ropar 140111, India \\ Correspondence should be addressed to Hitesh Verma; frd.ohcpl@gmail.com
}

Received 13 July 2015; Accepted 22 July 2015

Academic Editor: Christoph H. Saely

Copyright (C) 2015 H. Verma and R. Garg. This is an open access article distributed under the Creative Commons Attribution License, which permits unrestricted use, distribution, and reproduction in any medium, provided the original work is properly cited.

We read the research of Scaramuzza et al. [1], with great interest. The role of endothelial dysfunction in type 1 and type 2 diabetes is well evident and is related to various types of micro- and macrovascular complications associated with diabetes $[2,3]$. In their study, Scaramuzza et al. depict the role of alpha-lipoic acid in alleviating the symptoms of endothelial dysfunction but the study seems to be associated with two major limitations. First and foremost limitation of study is the selection of appropriate dosage in the study protocol. The present study is conducted at the dose regimen of $400 \mathrm{mg}$ twice daily (i.e., $800 \mathrm{mg} /$ day). The rationale behind the selection of dose does not seem to be justified. The authors designed their hypothesis based on the results available in type 2 diabetic patients. Though the authors mentioned that in type 2 diabetes patients $600 \mathrm{mg} /$ day dose is reported to produce significant benefits in endothelial dysfunction, still they used $800 \mathrm{mg} /$ day regimen, which was not justified. Moreover, the authors did not include some very important references in their review of literature which were conducted for alpha-lipoic acid usage in alleviating endothelial dysfunction associated symptoms in type 1 diabetic patients. These trials were conducted at the dose of $600 \mathrm{mg} /$ day and include adult population $[4,5]$. These could serve as the basis for selection of appropriate dose as in our view the trial should have been conducted at a dose not more than $600 \mathrm{mg} /$ day. Dose selection based on observation in type 2 diabetic patient seems to be inappropriate since endothelial dysfunction is more severe in case of type 2 diabetes which is often associated with various metabolic abnormalities (e.g., obesity, hypercholesterolemia, and hyperlipidemia) which is generally not the case in type 1 diabetic patients [3]. The second major limitation is the uncontrolled nature of the study; noncompliance among patients affects the study results. We appreciate the work of Scaramuzza et al., for starting the research of the possible role of alpha-lipoic acid in alleviating the endothelial dysfunction in young adolescent type 1 diabetic patients but future well-randomized, placebo controlled trials are required before coming on to some definite conclusion.

\section{Conflict of Interests}

The authors declare that there is no conflict of interests regarding the publication of this paper.

\section{References}

[1] A. Scaramuzza, E. Giani, F. Redaelli et al., "Alpha-lipoic acid and antioxidant diet help to improve endothelial dysfunction in adolescents with type 1 diabetes: a pilot trial," Journal of Diabetes Research, vol. 2015, Article ID 474561, 7 pages, 2015. 
[2] S. D. Funk, A. Yurdagul, and A. W. Orr, "Hyperglycemia and endothelial dysfunction in atherosclerosis: lessons from type 1 diabetes," International Journal of Vascular Medicine, vol. 2012, Article ID 569654, 19 pages, 2012.

[3] J. Calles-Escandon and M. Cipolla, "Diabetes and endothelial dysfunction: a clinical perspective," Endocrine Reviews, vol. 22, no. 1, pp. 36-52, 2001.

[4] R. Mollo, F. Zaccardi, G. Scalone et al., "Effect of $\alpha$-lipoic acid on platelet reactivity in type 1 diabetic patients," Diabetes Care, vol. 35, no. 2, pp. 196-197, 2012.

[5] M. Morcos, V. Borcea, B. Isermann et al., "Effect of $\alpha$-lipoic acid on the progression of endothelial cell damage and albuminuria in patients with diabetes mellitus: an exploratory study," Diabetes Research and Clinical Practice, vol. 52, no. 3, pp. 175-183, 2001. 


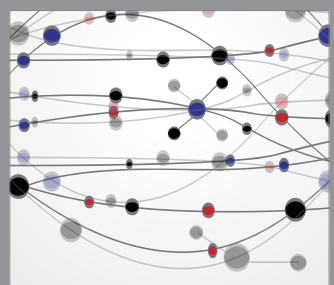

The Scientific World Journal


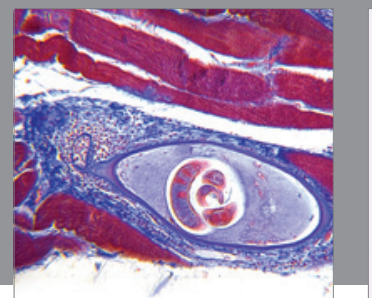

Gastroenterology

Research and Practice
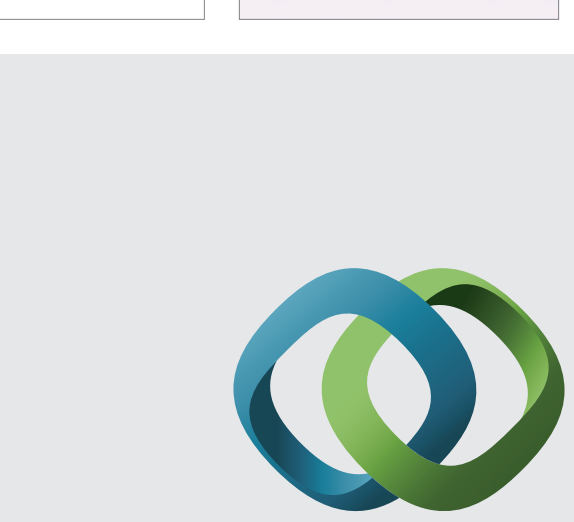

\section{Hindawi}

Submit your manuscripts at

http://www.hindawi.com

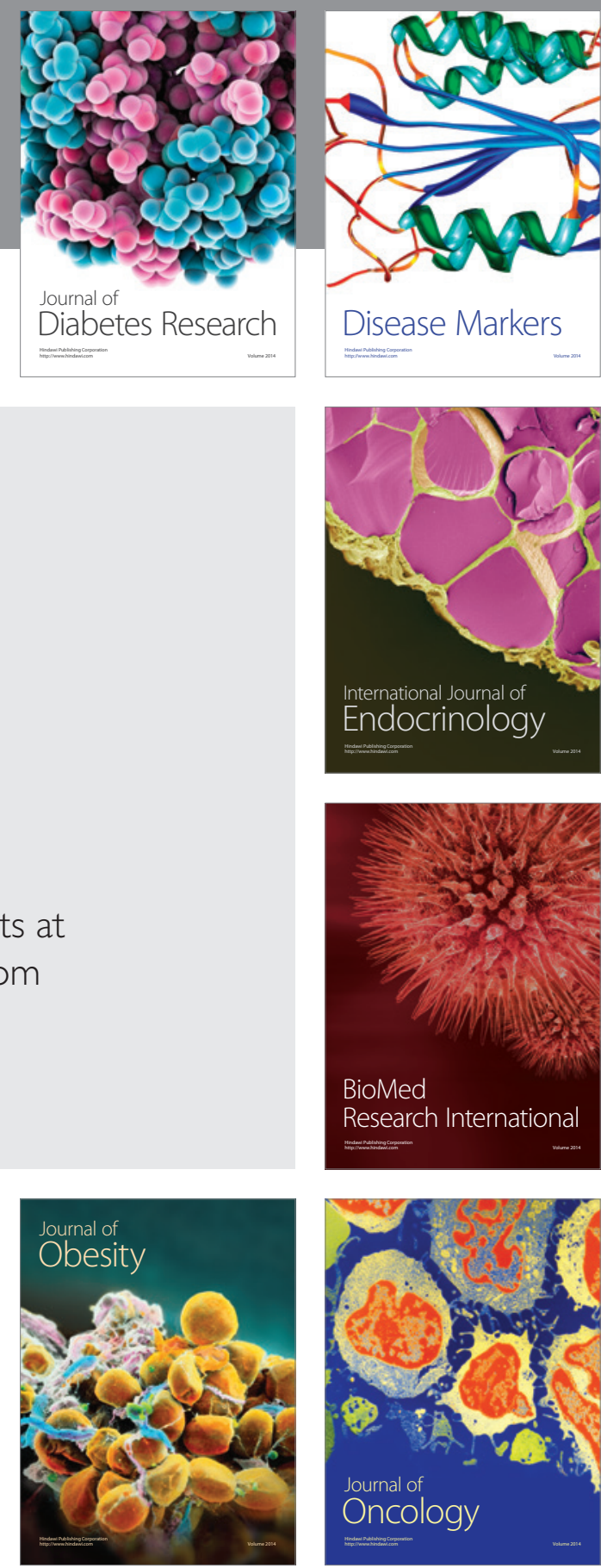

Disease Markers
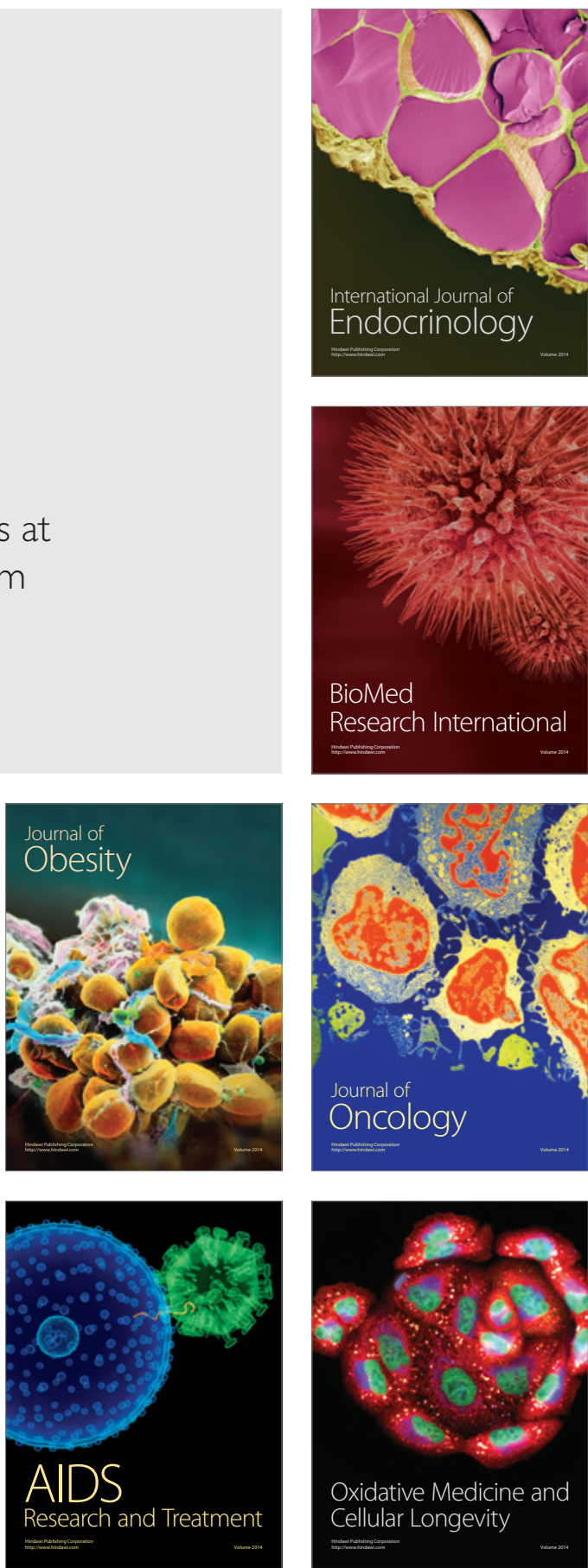